\title{
FORMAÇÃO PROFISSIONAL EM SERVIÇO SOCIAL - UMA ÊNFASE NO PROCESSO DE CONSTRUÇÃO DO TCC
}

Márcia Salete Arruda Faustini ${ }^{1}$ Véra Lúcia Carvalho Villar ${ }^{2}$

Resumo: O presente artigo é parte do produto de uma investigação qualitativa realizada junto a um Curso de Graduação em Serviço Social da região Sul do país com o propósito de contribuir na qualificação da formação profissional a partir da análise do processo de construção do TCC (Trabalho de Conclusão de Curso) em Serviço Social. O estudo contou com a participação de diplomados e docentes, bem como com a análise documental em TCCs e cogitou problematizar este processo de avaliação, tendo como referência o momento da elaboração do trabalho final. Pretendeu-se contribuir para a identificação de pontos positivos, dificuldades e sugestões do referido processo. Destaca-se a importância de problematizar permanentemente o processo de avaliação a partir da escuta da fala, no cotidiano, de quem protagoniza o processo formativo.

Palavras-chave: Serviço Social. Trabalho de Conclusão de Curso. Formação em Serviço Social. Diplomados. Docentes. 


\section{Uma incursão pelo contexto do Trabalho de Conclusão no Serviço Social}

O artigo aqui apresentado é parte do produto da análise realizada acerca do processo de construção do Trabalho de Conclusão de Curso (TCC) vivenciado por diplomados e docentes durante a sua elaboração, num curso de graduação em Serviço Social. Achados e reflexões aqui contidas constam no relatório de pesquisa original desta investigação (VILLAR, 2007).

Destaca-se que o TCC caracteriza-se como uma modalidade de trabalho acadêmico que expressa um momento de síntese da graduação e constituise em elemento obrigatório para a titulação em Serviço Social (ABEPSS, 1999; MEC, 2002). Segue normas técnicas vigentes, é elaborado pelo aluno sob a orientação de um professor-assistente social e pauta-se por critérios previamente definidos, submetido a um seminário de avaliação aberto ${ }^{3}$.

A investigação apresentou os seguintes objetivos: Analisar o processo de construção do TCC a partir da experiência de diplomados e de docentes de uma Unidade de Ensino de Serviço Social do sul do Brasil, visando subsidiar a qualificação curricular; identificar a materialização da avaliação dos indicadores dos TCCs na produção escrita do referido trabalho através da explicitação de sua presença/ausência no texto; descrever pontos positivos e dificuldades referentes ao processo de elaboração do TCC que podem auxiliar a qualificação de sua construção; elaborar sugestões acerca do processo de construção do TCC visando qualificar a formação profissional em Serviço Social ${ }^{4}$. Destaca-se que o presente artigo trabalha os dados referentes a explicitação do terceiro e do quarto objetivos.

O estudo de abordagem qualitativa foi a partir da análise em Trabalhos de Conclusão de Curso junto a diplomados e docentes (professoressupervisores, avaliadores e orientadores do TCC e professores de disciplinas), dentre outras questões, identificou alguns elementos que concorrem na concretização do trabalho final e na identificação de pontos positivos e dificuldades em sua materialização. ${ }^{5}$

A pesquisa teve como sujeitos: diplomados em Serviço Social pela referida Unidade Acadêmica durante o ano de 2005, cuja seleção teve como referência os trabalhos selecionados para a análise documental mencionada e, contou também, com professores do referido curso. 
Foi utilizada a análise documental (RICHARDSON, 1999), em quinze TCCs, selecionados através de amostra intencional estratificada, com recorte de trabalhos recomendados para consulta (sete) e de trabalhos que não foram recomendados para consulta no curso (oito) ${ }^{6}$.

Destaca-se também a utilização da observação e das anotações de campo (TRIVIÑOS, 1992), na perspectiva de registrar livremente informações que pudessem contribuir na ampliação da compreensão do fenômeno investigado.

Como roteiro de análise dos trabalhos foram utilizados os Indicadores e Critérios de Avaliação do TCC, anteriormente referidos.

Como instrumentos para coleta de dados junto aos sujeitos, foram utilizados: questionário com questões abertas (dez) para os diplomados e questionários com questões abertas (nove) para os professores. Quanto à participação dos professores foi estruturada uma subdivisão a partir da seguinte categorização: professor-orientador, professor-avaliador, professorsupervisor e professor de disciplina. Realizou-se entrevista, utilizando um roteiro semi-estruturado, para um professor que solicitou complementar as respostas de seu questionário. Utilizou-se o "Termo de Consentimento Informado" e o material degravado e transcrito da entrevista, e disponibilizado para devolução ao sujeito participante.

Para organizar o material, foram confeccionados três painéis fixados na parede de sala reservada à pesquisa, reunindo os dados provenientes da análise documental nos TCCs; questionários com diplomados e professores, entrevista, observações, anotações de campo e referências da investigação.

Foram seguidos alguns procedimentos da orientação de (BARDIN, 1977) e (MORAES, 1999) para a análise de conteúdo, condizentes com os objetivos e questões norteadoras da investigação.

$\mathrm{Na}$ "Pré-análise", foi realizada a leitura flutuante no material para a preparação do corpus para a análise. No momento da "Unitarização" foram definidas as unidades de análise, que, posteriormente agrupadas, serviram de estrutura para a técnica da triangulação (TRIVIÑOS, 1992) - com os dados - de onde emergiram as categorias para compor a fase de "Categorização". Prosseguiu-se para a análise final, estabelecendo a articulação entre o material obtido e os referenciais teóricos da pesquisa, procurando as respostas para os objetivos da investigação. 
Quanto à conclusão do estudo, segundo Minayo (1992, citada, por MINAYO, 2004, p. 79): "o produto final da análise de uma pesquisa, por mais brilhante que seja, deve ser sempre encarado de forma provisória e aproximativa".

Com esta percepção o presente artigo sintetiza alguns aspectos referentes aos achados da investigação no que concerne a problematizar a avaliação e o processo de construção do TCC, bem como tecer sugestões para sua qualificação.

\section{A avaliação}

\section{Construindo o conhecimento}

Entendemos a avaliação como um processo fundamental no movimento de construção de conhecimento. Neste sentido, deve fazer parte do processo de construção e reconstrução da aprendizagem, mobilizado pelo aluno, durante os anos de sua formação. Segundo Enricone in: Enricone \& Grillo (2003, p. 55):

Relações a serem refletidas que demandam análises complexas são: entre ensinar e aprender; aprender e avaliar; ensinar e avaliar. $\mathrm{O}$ processo de avaliação pode identificar problemas de aprendizagem e encaminhar decisões para a superação destes, possibilitando a descoberta de modos de ensinar e de melhor acompanhar a aprendizagem. Deve criar-se no professor uma atitude avaliadora que é continuamente aprendida e é parte do processo educativo.

Grillo na mesma obra (2003, p. 21) traz ainda que: “A avaliação como processo é, pois, uma constante na ação educativa, seja entendida como base para a atividade do professor ou como diagnóstico da aprendizagem do aluno".

Compreendemos que a avaliação contribui para a sistematização da aprendizagem e pode enriquecer o conjunto de conhecimentos do aluno, através da reflexão e do diálogo entre docentes e discentes, no processo de ensino-aprendizagem. Consideramos importante ilustrar com as concepções de Hoffmann (1993, p. 153) sobre "aprender e avaliar": 
A aprendizagem significa descobrir a razão das coisas e pressupõe a organização das experiências vividas pelos sujeitos numa compreensão progressiva das noções. Avaliação significa ação provocativa do professor, desafiando o educando a refletir sobre as situações vividas, a formular e reformular hipóteses, encaminhando-se a um saber enriquecido. Dialogar é refletir em conjunto (prof. e aluno) sobre o objeto de conhecimento. Exige aprofundamento em teorias de conhecimento e nas diferentes áreas do saber. Acompanhar é favorecer o "vir a ser" desenvolvendo ações educativas que possibilitem novas descobertas.

Portanto, a avaliação pode "construir e reconstruir" o conhecimento do discente e do docente - através do diálogo entre professores e alunos.

\section{Concretizando a avaliação}

Entendemos a avaliação como: um momento de reflexão e de interação entre docente e discente; um movimento de transformação e aprimoramento de conhecimentos; um processo cujos critérios, necessitam de uma "avaliação" periódica, pois têm como função, auxiliar: os professores avaliadores na verificação do Trabalho Escrito e Seminário; os professores orientadores durante a orientação; e os alunos na construção do TCC.

Ao realizarmos a análise nos TCC(s), identificamos que alguns seguem, rigorosamente, os indicadores de avaliação existentes, o que sinaliza a compreensão adequada dos critérios estabelecidos pelo curso. Entretanto, outros trabalhos pontuam menos itens que compõem os indicadores, o que provavelmente dificultou a elaboração do mesmo. Sobre a interpretação adequada dos indicadores pelo aluno, citamos a opinião de um professor:

Eu acho que estes parâmetros até que são bem objetivos. Claro, tem uma terminologia que às vezes o aluno tem alguma dificuldade de entendimento, mas eu acho que os indicadores contemplam todas as dimensões que se exige na formação. Nem todos os alunos percebem... algumas coisas que são exigidas.

A avaliação, como parte de um processo de educação, deve promover 
momentos de debates sobre os seus parâmetros, considerando as diferenças e subjetividades dos docentes, como também dos discentes. Idéia reforçada por Grillo in: Enricone \& Grillo (2003, p.13-14):

Uma peculiaridade da avaliação é que ela incide, ao mesmo tempo, sobre diferentes instâncias envolvidas no processo educativo, como professores e alunos [...]. Confronta-se ainda com a questão da diversidade de avaliadores e avaliados, de diferenças e subjetividades, o que faz com que sejam atribuídos diversos significados à avaliação e conferidos tratamentos também diversificados.

Portanto, mesmo com os indicadores auxiliando a avaliação, cada professor tem a sua subjetividade, a sua própria maneira de interpretar tais indicadores. Conseqüentemente, pesa também o entendimento particular de cada um, fato este que alguns professores apontam como dificuldade para concretizar a própria avaliação, confirmado na opinião de um deles: "Penso que o instrumento que orienta o avaliador pudesse ser trabalhado melhor entre os professores avaliadores, visando a discutir aspectos subjetivos a partir do olhar diferenciado de cada avaliador". Como é um processo educativo entre professores e alunos, entendemos que a subjetividade do discente também deverá ser considerada.

Esse momento é importante para o processo formativo do Assistente Social e confirma-se com o pensamento de Paulo Freire (2004, p. 22): “A reflexão crítica sobre a prática se torna uma exigência da relação Teoria/ Prática sem a qual a teoria pode ir virando blablablá e a prática, ativismo”.

Identificamos que um grande número de alunos começa a pensar na elaboração do Trabalho de Conclusão de Curso quando inicia o estágio, o que se confirma com algumas respostas de diplomados, a seguir: "Comecei a pensar sobre a elaboração do TCC desde o começo dos estágios curriculares. Tive o cuidado em escolher um bom campo de estágio, supervisores de campo responsáveis e atuantes e o tema que me apaixonei”. Outro: "O TCC começou a ser pensado, logo no início do estágio curricular. Porém, já tinha clara a idéia de qual segmento gostaria de evidenciar. Dessa forma, fui direcionando todos os trabalhos de aula, leitura de textos, livros, que abordassem o tema". Mais um: "As 
documentações que subsidiaram sua construção se iniciaram com os estágios".

O Trabalho de Conclusão de Curso tem como referência o estágio, mas, a construção do conhecimento do aluno (que está em permanente transformação) ocorre, de uma forma especial, durante os anos de formação em que permanece na academia - o TCC é uma síntese final desse período - por isso, essa síntese que encerra um ciclo é que precisa ser avaliada, na opinião de alguns professores.

A elaboração do trabalho final já pode ser pensada desde quando o aluno ingressa no curso, pois todos os conteúdos aprendidos e apreendidos são componentes fundamentais para a construção da formação profissional.

O TCC é uma forma de materializar conhecimentos através da linguagem escrita e oral, propiciando possíveis correções e reconstruções do pensamento. É um momento em que o aluno elabora uma síntese crítica - integrando e sistematizando conhecimentos adquiridos no transcorrer do curso e nas vivências de estágios - avaliando e refletindo teoricamente sobre o movimento do saber e da realidade da ação profissional com um olhar mais ampliado no qual sintetiza conhecimentos e pode projetar novos desafios.

\section{A edificação do trabalho: O TCC \\ Construindo o objeto do TCC}

Verificamos que alunos e professores referem uma certa dificuldade em construir o objeto do TCC, o que se confirma no pensamento a seguir: "A maior dificuldade é construir teoricamente sobre a temática. O próprio orientador tem de fazer grande esforço para estar atualizado nos diversos temas".

O tema e sua delimitação é uma escolha do aluno, e percebemos que esta opção se dá porque existe uma afinidade teórico-prática com determinado assunto. Se for bem selecionado, poderá ajudar no processo de elaboração do TCC, propiciando ao aluno uma visão crítica que se faz fundamental na síntese final do curso. Entretanto, se o tema for mal delimitado e se não houver conhecimentos suficientes por parte do orientador sobre a temática, poderá haver um comprometimento no processo de edificação do trabalho.

A análise dos dados nos fez perceber que alguns trabalhos materializam 
uma certa dificuldade em articular conteúdos teóricos agregados durante o curso com a expressão da prática no campo de estágio, o que se reflete na dificuldade de expressar a unidade das dimensões da competência profissional do assistente social: ético-política; teórico-metodológica e técnico-operativa, indicadas nas Diretrizes Curriculares do curso.

$\mathrm{Na}$ percepção da maioria dos professores e diplomados, todas as disciplinas que compõem a grade curricular auxiliam na construção do Trabalho de Conclusão de Curso, contudo, há algumas específicas para este fim. Verificamos que na concepção dos sujeitos investigados, o papel do professor é fundamental para que o trabalho se concretize satisfatoriamente. Segundo o parecer de um professor: "Todas as disciplinas devem compor o TCC, cabendo a todos os professores perseguir a articulação entre os diferentes conteúdos que vão dar conta da formação". Essa concepção confirma-se na opinião de outro professor:

Todas as disciplinas de formação em Serviço Social podem ajudar diretamente para esta construção, tanto quanto disciplinas de áreas afins também podem estar contribuindo. Depende da possibilidade de articulação que o aluno vai construindo ao estudar os conteúdos e do empenho dos professores ao prepararem os conteúdos tendo em vista subsidiar a relação com a prática dos alunos.

Entendemos que depende também dos conhecimentos que o aluno aprendeu, apreendeu e acumulou das matérias cursadas, bem como, da possibilidade e capacidade de fazer a articulação com esses saberes.

Neste sentido, constatamos que o orientador tem um papel muito importante na elaboração do trabalho escrito, sendo fundamental a existência de uma 'harmonia' e um 'bom entrosamento' entre ele e o aluno para que o processo de construção do conhecimento se efetive. Alunos apontam que, quando o orientador demonstra dificuldades para o feedback, há um prejuízo no processo de orientação como um todo, visto que este 'retorno' é indicador de um processo de qualidade, assim como a segurança, a acolhida, a crítica e a sugestão por parte da figura da orientação afirmamse como geradoras de reflexão para o aluno.

A elaboração do TCC pode gerar momentos de tensão, por constituir o fechamento de um ciclo, e muitos alunos podem demonstrar insegurança quanto a sua produção. Então, se faz necessário que o professor adote 
uma intervenção pedagógica, a partir da estimulação e da ajuda, para que o aluno busque e adquira conhecimentos e para que esteja apto a reconhecer os desafios da realidade que está vivenciando e, conseqüentemente, aja adequadamente. Vasconcellos (1999, p. 52) afirma que:

Significar um objeto de conhecimento, para que o sujeito se debruce sobre ele, implica uma ação educativa no sentido de provocar, desafiar, estimular, ajudar o sujeito a estabelecer uma relação pertinente com o objeto, que responda, em algum nível, à satisfação de uma necessidade sua, mesmo que essa necessidade não estivesse tão consciente de início.

Algumas funções do orientador são de instigar, de facilitar, de ajudar, de criar condições para a aprendizagem do aluno. O que se confirma na seguinte opinião:

$\mathrm{O}$ orientador tem que inicialmente contribuir para que o aluno possa re-olhar para o seu projeto de TCC e no decorrer de todo processo de construção do TCC, instigar a reflexão e problematizar acerca dos elementos que devem estar presentes na elaboração teórica (PROFESSOR).

O que é ratificado na opinião de um diplomado:

Acredito que o papel da orientação é fundamental no processo de construção do TCC, pois é neste momento que o aluno precisa ter tranqüilidade, segurança. Ao mesmo tempo, necessita que o orientador lhe sinalize em quais aspectos o trabalho pode ser melhorado, sugira onde buscar bibliografias, leia e se atualize sobre o tema, para melhor interagir e orientar o aluno, que cobre, que motive, que impulsione.

Observa-se a indicação da necessidade de se pensar na possibilidade de um remanejo de orientadores quando forem constatados sérios problemas de entrosamento entre orientador e orientando, pois, possivelmente a permanência desta relação poderá prejudicar o processo de construção do trabalho. Segundo Werneck (2000, p. 77): “Uma escola 
de qualidade precisa ser mais solidária, percebendo as necessidades dos alunos". Idéia partilhada por um diplomado:

Acredito que a orientação deveria ser dada de forma clara, ampla e que respeitasse a criatividade do acadêmico. O orientador deveria questionar, problematizar e avançar de acordo com o ritmo do orientando. Acredito que se o orientando não consegue entender totalmente o orientador que é disponibilizado pelo curso, pudesse ter outra alternativa, para não prejudicar a construção do TCC, pois esse é um momento único na vida do (a) formando (a).

O papel do orientador é muito importante no processo de construção do trabalho escrito, entretanto, os saberes acumulados pelo educando durante todo o decorrer do curso são imprescindíveis para este momento de síntese final, como está claro na opinião deste professor:

Se o aluno vier para a orientação sem uma boa base anterior de desenvolvimento de análise e interpretação da sua experiência e com uma boa bagagem de leituras e sínteses, não há como fechar o processo de aprendizagem na construção de um TCC. A orientação é parte do momento finalístico e, anterior a este, tem que ter se edificado um significativo processo de construção teórico-prática. $\mathrm{O}$ curso vai possibilitando vários momentos anteriores para este exercício nas disciplinas, nos laboratórios e especialmente no material exigido pela supervisão.

Para ilustrarmos o papel do professor no processo de ensinoaprendizagem, recorremos a Rios (2006, p. 96) com a definição de "práxis docente competente":

Para que a práxis docente seja competente, não basta então, o domínio de alguns conhecimentos e o recurso a algumas "técnicas" para socializá-los. É preciso que a técnica seja fertilizada pela determinação autônoma e consciente dos objetivos e finalidades, pelo compromisso com as necessidades concretas do coletivo e pela presença da sensibilidade, da criatividade. 
Portanto, para que ocorra competência no ensino-aprendizagem se faz necessário que, além dos conhecimentos adquiridos pelos educandos durante todo o curso, os educadores, com seus saberes tenham também sensibilidade e habilidades para atingir os objetivos propostos.

\section{Critérios de avaliação}

Percebemos a importância de o formando ser comunicado - durante o seminário de avaliação do TCC - sobre o que pode ser aprimorado no seu trabalho escrito. Com esta atitude, os professores estão possibilitando o aperfeiçoamento dos conhecimentos do aluno. E, segundo Enricone in:Enricone \& Grillo (2003, p. 135): “A avaliação, portanto, deve servir à formação do aluno, ser usada em favor da aprendizagem e ter melhor explorado seu potencial educativo".

Constatamos, nas percepções de alguns diplomados e professores, uma certa problematização em relação aos "critérios de avaliação" do trabalho final e alguns aspectos em relação ao ensino-aprendizagem desenvolvidos durante os anos de curso. Aparece, em alguns depoimentos, a exigência de que - no TCC - possam ser 'cobradas' questões que deveriam ter sido superadas ao longo do processo formativo ou na supervisão, ou então de que - no TCC - não seja suficientemente considerado o quanto o aluno aprendeu, mas sim, o quanto ainda não conseguiu aprender. Um professor refere a importância de se reconhecer os avanços que foram possíveis de serem construídos ao longo do processo de orientação, não limitando a análise/avaliação somente ao que não fora alcançado.

Neste sentido, percebe-se que algumas dificuldades encontradas no processo avaliativo exigem uma permanente discussão acerca das concepções sobre avaliação por parte dos sujeitos envolvidos.

\section{Critérios de avaliação}

\section{Para qualificar o processo}

Ao analisarmos as percepções dos professores, observamos que existe a preocupação com a realização de diálogo - parte integrante do processo de “aprender e avaliar" - e, segundo Hoffmann (1998, p. 153): “Dialogar 
é perguntar e ouvir respostas. Acompanhar significa estar sempre junto para observar e registrar resultados". Esta questão corrobora com a manifestação de um professor: "Como sugestão, penso que cada orientador pudesse realizar seminários mensais com seus supervisionados, visando discussões coletivas sobre o processo de construção do TCC".

Verificamos sugestões sinalizando para a qualificação do processo de construção do TCC que apontam alguns aspectos a serem considerados: a realização de debates sobre as temáticas dos TCCs; a qualificação permanente da relação de ensino-aprendizagem entre alunos e supervisores; a qualificação de esforços por parte dos formandos para a apresentação oral; e, a atenção por parte dos alunos, ao cursarem as disciplinas que subsidiam o TCC, em selecionar bibliografias - com temas de seu interesse - que auxiliarão na elaboração do trabalho.

Percebemos durante o desenvolvimento da investigação, um considerável interesse por parte dos sujeitos envolvidos no processo, em conhecer os resultados deste estudo, o que denota o compromisso de todos com a formação profissional, como também a importância da investigação para a qualificação do processo de construção do TCC.

A investigação apresenta-se com um "diferencial" que propicia a "reconstrução", que segundo Demo (2000, p. 1):

[...] definição de educação como processo de formação da competência humana, com qualidade formal e política, encontrando no conhecimento inovador a alavanca principal da intervenção ética. O critério diferencial da pesquisa é o questionamento reconstrutivo, que engloba teoria e prática, qualidade formal e política, inovação e ética.

Portanto, a partir desses estudos, são potencializadas "ações transformadoras e reconstrutivas", procedimentos fundamentais para construir uma educação competente. A reflexão da prática, conforme Schön (1992, apud Busato, 2005, p. 59):

O processo de reflexão da prática político-pedagógica pode se desenvolver em dois momentos: a reflexão-na-ação e a reflexãosobre-a-ação. A reflexão-sobre-a-ação pode ser considerada como 
a análise que é realizada após a efetivação de uma determinada ação, utilizando-se de conhecimentos já construídos, de relações estabelecidas com o cotidiano no qual se processou a ação. Por sua vez, a reflexão-na-ação desenvolve-se à medida que se faz, se executa determinada prática. Ao mesmo tempo em que se faz a ação, reflete-se o pensamento-em-ação.

Percebemos uma certa preocupação por parte de alguns professores no que se refere às condições para a qualidade da Supervisão de Campo no processo de ensino-aprendizagem do estagiário. O estágio curricular obrigatório deve qualificar a formação do aluno e, a construção do TCC, ligada a essa experiência, pressupõe investimento permanente na qualidade da parceria entre Assistente Social de Campo e o Professor-Supervisor.

Conforme Perrenoud (2002, apud Lopes, 2006 p. 155): "os formadores trabalham, refletem, formam-se, inovam, mas com freqüência cada um continua no seu canto". E Lopes (2006, p. 155 -156) evidencia as responsabilidades neste processo:

A supervisão de estágio se dá num movimento articulado, dialético e reflexivo entre os atores deste processo: professor supervisor, assistente social supervisor e aluno estagiário, onde os saberes se permeiam propiciando o desenvolvimento de competências necessárias para o saber e o fazer profissional. [...] Esses atores do processo de supervisão são imprescindíveis, cabe, na formação profissional, definir e potencializar cada um deles, para que se reconheçam e possam então assumir seus compromissos, responsabilidades, atribuições e competências neste processo.

Como vimos, o TCC expressa uma síntese final da graduação. Se o aluno dispuser de um manual detalhado (embora - registre-se - existem critérios escritos e trabalhados com os alunos que, inclusive, foram redefinidos no ano desta investigação), como sugere o professor, com diretrizes do processo de construção do trabalho escrito e da apresentação oral, provavelmente, este momento de finalização do Curso será de mais fácil compreensão para os discentes e o produto final apresentará mais qualidade. 


\section{Para a apresentação}

Solicitamos aos professores que, também, pontuassem sugestões para a apresentação do TCC. Observamos que a maioria dos docentes defende a permanência da forma atual de apresentação, em sequiência: a elaboração de um artigo, a confecção de um pôster e outras formas de socialização do trabalho. A seguir, destacamos algumas sugestões: "Monografia é a minha primeira sugestão, embora não faça restrição a artigo".

Penso que a forma atual tem sido boa, garante um espaço de discussão com o aluno, mas ao mesmo tempo, penso que a organização do TCC em um artigo poderia representar um outro patamar de produção científica e visibilidade para os trabalhos produzidos. Mas a dificuldade maior é, como garantir a sua produção após a apresentação do TCC (PROFESSOR).

Portanto, a maneira como é realizada, a apresentação do trabalho, pela Unidade de Ensino participante da investigação, na concepção dos professores, é satisfatória. Entretanto, os docentes apontam sugestões que poderiam beneficiar este processo, como: artigo; pôster, socialização do trabalho em outros ambientes e a presença do Professor-Supervisor durante a apresentação.

[...] que possa se tornar um artigo e de igual forma possa traduzir-se em um pôster para uma exposição. O seminário aberto já acontece e o ideal é que o aluno pudesse aproveitar o conteúdo de seu TCC para apresentar em outros espaços para além do curso, como por exemplo, no seu campo de estágio, nas instituições com as quais teve alguma interlocução, para os usuários de seu serviço (PROFESSOR).

O seminário de apresentação oral é um espaço de "crítica-reflexiva da produção do discente" e também, parte integrante da "construção de conhecimento" para o formando, para a comissão avaliadora e para quem assiste a apresentação. Entretanto, como todo processo que busca qualificação, necessita estar permanentemente problematizado. Os diplomados também elencam fatores para a qualificação do TCC. 


\section{Sugestões dos diplomados}

\section{Para qualificar o processo}

Ao analisarmos os dados dos diplomados, constatamos que a maioria entende que há necessidade de dois semestres para a construção do TCC - o tempo disponibilizado foi um dos fatores que dificultou a realização do Trabalho Escrito - e sugerem que o trabalho seja contemplado com todo o último ano do curso, para sua concretização. Exemplificamos com a sugestão de um diplomado: "Que os alunos tenham acesso a esta construção nos dois semestres finais e não somente no último,... para que desta forma se tenha um maior aproveitamento no momento final da concretização do TCC".

Os diplomados também forneceram sugestões sobre a avaliação e sobre a orientação. Há sugestão de que os critérios de escolha do orientador, por parte do curso, levem em consideração aquele professor que tenha acompanhado o processo de aprendizagem daquele aluno, especificamente, ao longo do curso; que o aluno possa contar com a presença do orientador na apresentação do TCC, e que se considere a possibilidade de avaliação do processo de orientação por parte do aluno, destacando a relação construída.

A avaliação de professores realizada pelos alunos, segundo Cabanach (1999, apud Enricone in: Enricone \& Grillo, (2003, p. 136): 'proporciona, em conjunto, o melhor critério de qualidade da instrução, dado que os estudantes são os mais fiéis observadores da atuação docente'. E, a autora complementa: "Como o estudante é um participante ativo no processo de aprendizagem e está em situação privilegiada para proporcionar dados sobre certos aspectos do comportamento do professor, deve ser também um protagonista na avaliação do ensino".

E, assim, encaminhando-nos para as considerações finais, gostaríamos de destacar duas questões: temos conhecimento de que algumas das sugestões aqui indicadas já estavam em fase de efetivação, no curso participante da investigação, por ocasião da pesquisa; temos também, como contribuição ratificar a importância de investigações sobre questões cotidianas do ensino-aprendizagem no Serviço Social a fim de que se possa, permanentemente, estar qualificando os rumos que se pretende dar a formação profissional. 


\section{CONSIDERAÇÕES FINAIS}

Considerando a proposta de contribuir com a formação profissional em Serviço Social a partir da problematização do processo de construção do TCC, podemos identificar:

* Pontos Positivos:

- Aimportância da existência de uma boa "sintonia" entre orientando e orientador.

- A potencialização dos momentos de reflexão e avaliação do processo de ensino-aprendizagem.

- A efetivação de supervisores com as habilidades necessárias ao acompanhamento do estágio.

- O desejo por parte do aluno de "fazer bem" e estar atento, permanentemente, ao processo de aprendizagem, buscando constantemente a construção do conhecimento.

- A atenção por parte do aluno sobre a elaboração do TCC que deve estar presente - em sua mente e coração - desde o início do curso, acumulando e mobilizando aprendizagens de conteúdos das disciplinas.

- A consciência de alunos e professores de que todas as disciplinas auxiliam a construção do TCC.

- A articulação entre disciplinas que dão sustentação ao trabalho.

- A presente perspectiva de que a avaliação é um processo de construção e reconstrução da aprendizagem.

\section{* Dificuldades:}

- Do aluno em articular a teoria com a prática e delimitar o tema do trabalho, por uma dificuldade de percepção desta articulação.

- Do estagiário em apropriar-se teoricamente de sua intervenção, o que se reflete, no momento de compreender as particularidades do objeto de intervenção e do objeto de TCC.

- De lidar com os limites do tempo de construção. Compreender e criar estratégias frente aos limites em relação ao tempo disponibilizado pelo aluno que, em grande parte das vezes, é também trabalhador. 
- De lidar com o tempo de orientação, que sofre restrições de planilha administrativa nas Unidades de Ensino.

- Do aluno em cumprir a seriação aconselhada pela grade curricular. Os alunos deixam de cursar disciplinas que subsidiam o trabalho - no momento, pedagogicamente, mais adequado - tendo em vista a realidade de trabalho que vivenciam, custos no semestre, etc.

- De lidar com a dimensão subjetiva presente em todo o processo de avaliação.

Entendemos que a avaliação é parte muito importante no processo de ensino-aprendizagem, sendo imprescindível durante todo o desenrolar do curso até o momento de síntese final. É fundamental que exista coerência entre a avaliação e o que foi ensinado. Conforme Enricone in: Enricone \& Grillo (2003, p. 53):

Assim como os propósitos de avaliação podem ser diversos e ela é também uma atividade que deve ser desenvolvida em diferentes momentos do processo ensino-aprendizagem, o professor, como profissional de docência, precisa coerência entre ensinar e avaliar.

Elencamos "sugestões acerca do processo de construção do TCC" visando qualificar a formação profissional em Serviço Social.

\section{* Sugestões:}

- Oportunização de momentos para seminários mensais, com orientador e orientandos, visando a discussões coletivas sobre o processo de construção do TCC.

- Realização de pesquisas bibliográficas sobre as temáticas nas disciplinas (direcionar os trabalhos propostos nas disciplinas visando a contemplar os temas escolhidos).

- Intensificação de pesquisas bibliográficas sobre a própria prática no ensino superior, visando a clarificar peculiaridades e particularidades ao campo didático-pedagógico no ensino superior.

- Ampliação de espaços de parceria efetiva entre o Assistente Social de Campo e o Professor-Supervisor (participação conjunta em seminários).

- Construção de uma cultura em que a apresentação do TCC tornese um evento significativo (socializar com amigos, familiares, Assistente Social de Campo, colegas de campo de estágio, etc.). 
- Qualificação do manual de orientações para alunos-formandos sobre a construção do TCC - já existente, intensificando sua consistência na perspectiva de que o aluno deve estar atento para o objeto de trabalho, para as questões teórico-metodológicas, ético-políticas e técnico-operativas, reforçando aspectos estruturais do trabalho escrito. Listar sugestões para o Seminário de apresentação destacando atribuições de aluno e orientador.

- Construção de estratégias pedagógicas que intensifiquem a atenção ao TCC por parte das disciplinas alocadas, especialmente, no ultimo ano do curso - qualificando permanentemente o movimento realizado no currículo - pelas disciplinas indicadas (inclusive pelos alunos) que dão sustentação à elaboração do TCC.

- Qualificação permanente da relação com o orientador: que exista uma "sintonia" entre orientando e orientador - que o professor indicado para orientação possa ser um docente que esteja acompanhando o processo formativo do aluno no decorrer do curso.

- Potencialização para a avaliação sobre o processo e não somente sobre o produto da aprendizagem do aluno, bem como a avaliação sobre o processo de orientação.

- Promoção de atividades de socialização do TCC, pelo diplomado, no local das experiências de estágio; espaços coletivos de discussão dos trabalhos em construção e com alunos já formados.

- Garantia de que os professores avaliadores sigam o mesmo manual de normas técnicas de ABNT, e trabalhado com os formandos, não só no TCC, mas ao longo da formação.

- Qualificação permanentemente da articulação entre as disciplinas que corroboram na construção do TCC.

- Criação de mecanismos no TCC para que fique registrado no trabalho sua avaliação com os critérios e pontuações explicitadas, garantindo ao formando e a um possível leitor o acesso a um parecer sobre o trabalho.

- Criação de estratégias para oportunizar a presença do ProfessorSupervisor, do Assistente Social de Campo e Orientador durante a apresentação oral, objetivando um processo de aprendizagem coletivo, valorizando espaços e funções na formação.

Finalizando este estudo, gostaríamos de destacar a importância de pensar sobre a prática cotidiana da formação profissional. Nunca paramos 
de aprender e nunca estaremos prontos - aí reside nossa humanidade, pequenez e beleza. Mas também reside nossa potência de sempre buscarmos fazer melhor. Para tanto, precisamos ter a humildade de aceitar nossas incompletudes e nossos não saberes e ir buscar...

Problematizar o processo formativo em Serviço Social, e, em especial, o processo de construção do TCC nos remete a este movimento intenso e necessário de qualificar a formação profissional não somente a partir das fontes teóricas e essenciais que iluminam nossas possibilidades de saber, mas também a partir dos sujeitos protagonistas deste movimento de formação. Considerar suas percepções e vozes é fundamental para operar mudanças que se assentam no real e que buscam assumir o compromisso no cotidiano da formação de qualificar permanentemente o processo de ensino-aprendizagem em Serviço Social.

\section{Notas}

${ }^{1}$ Orientadora da Pesquisa, Assistente Social, Mestre em Serviço Social, Doutora em Educação, Professora da Faculdade de Serviço Social da PUCRS.

${ }^{2}$ Assistente Social, Mestranda em Serviço Social da PUCRS. No transcorrer da pesquisa era Bolsista de Iniciação Científica - BPA/PUCRS (2006). Obteve o primeiro lugar na área Ciências Sociais Aplicadas na premiação do VII Salão De Iniciação Científica da PUCRS - Outubro/2006.

3 "O Trabalho de Conclusão de Curso é uma monografia científica que se caracteriza por ser uma atividade curricular obrigatória, realizada sob orientação de um professor assistente social para a obtenção de diploma de graduação de Serviço Social, contemplando aspectos teórico-metodológicos, técnico-operativos e ético-políticos”. Estes, acrescidos aos aspectos estruturais do trabalho, desdobram-se em indicadores específicos de avaliação do TCC (trabalho escrito). A nota final do trabalho é composta a partir da pontuação destes indicadores juntamente com "indicadores de avaliação no seminário" (referentes à apresentação oral). (Documento Institucional. Programa da Disciplina de TCC 2005/ 2, p. 1-2). O seminário aberto possibilita com que outros alunos e demais interessados possam assistir a este momento tão significativo na formação profissional. Por ocasião desta investigação o curso realizou uma revisão na sistematização dos critérios deste processo. (Documento Institucional. Indicadores e Critérios de Avaliação do Trabalho de Conclusão de Curso - Escrito e Oral. 2006).

${ }^{4}$ A presente pesquisa integra um conjunto de investigações acerca do tema formação profissional em Serviço Social desenvolvidas sob a coordenação e orientação da professora Márcia Faustini que destacam a preocupação com temáticas voltadas ao cotidiano pedagógico da formação na área.

${ }^{5}$ Para a realização desta investigação contou-se com o apoio da BPA/PUCRS - com Bolsa de Iniciação Científica.

${ }^{6}$ Após o Seminário de Apresentação do TCC a Comissão Avaliadora procede a avaliação do trabalho em sua dimensão escrita e oral, tendo como referência os critérios e indicadores 
de avaliação. Os trabalhos recomendados para consulta ficam arquivados e são disponibilizados, no curso, para acesso de outros alunos, os demais trabalhos são encaminhados ao arquivo da Unidade de Ensino como documentação.

\section{Referências}

ABEPSS. Diretrizes Curriculares para o curso de Serviço Social - Comissão de Especialistas em S.S. Brasília, Fevereiro de 1999.

BARDIN, Laurence. Análise de conteúdo. Lisboa: Edições 70, 1977.

BUSATO, Zelir S. L. Avaliação nas Práticas de Ensino e Estágios: a importância dos registros na reflexão sobre a ação docente. Porto Alegre: Mediação, 2005.

DEMO, Pedro. Educar Pela Pesquisa. 4. ed. (Coleção educação contemporânea) Campinas, SP: Autores Associados, 2000.

DOCUMENTO InSTITUCIONAL. Programa da Disciplina de TCC. 2005/2. . Indicadores e Critérios de Avaliação do Trabalho de Conclusão de Curso-Escrito e Oral. 2006.

ENRICONE, Délcia \& GRILLO, Marlene. Avaliação: uma discussão em aberto. Porto Alegre: EDIPUCRS, 2003.

FAUSTINI, Márcia S. A \& VILLAR, Véra L. C. \& WEIZENMANN, Martha H. Formação Profissional em Serviço Social numa perspectiva educativo-crítica: mobilizando mediações político-pedagógicas em sala de aula. Revista Textos \& Contextos. Porto Alegre, V 6, Nº 1, p. 191-196. jan./jun. 2007.

FREIRE, Paulo. Pedagogia da Autonomia: Saberes necessários à prática educativa. São Paulo: Paz e Terra, 2004.

HOFFMANN, Jussara. Avaliação Mediadora. Porto Alegre, RS: Editora Mediação, 1993.

LOPES, Maria S. M. Formação Profissional no Serviço Social: Desafios e Possibilidades do Assistente Social Supervisor de Campo. Dissertação de Mestrado em Serviço Social. FSSPUCRS. 2006. 
MEC-Diretrizes Curriculares para o Curso de Serviço Social. Res. 15 13/março 2002.

MINAYO, Maria C. de S. Pesquisa Social: Teoria, método e criatividade. Petrópolis, RJ: Vozes, 2004.

MORAES, Roque. Análise de Conteúdo. In: Educação Porto Alegre, Ano XXII, No.37, 1999.

PERRENOUD, Philippe. Construir as competências desde a Escola. Porto Alegre: Artes Médicas Sul, 1999.

RICHARDSON, Roberto J. Pesquisa Social: Métodos e Técnicas. São Paulo: Atlas, 1999.

RIOS, Terezinha A. Compreender e ensinar: por uma docência de maior qualidade. São Paulo: Cortez, 2006.

TRIVIÑOS, Augusto N. S. Introdução à Pesquisa em Ciências Sociais. São Paulo: Atlas, 1992.

VASCONCELLOS, Celso dos S. Construção do Conhecimento em Sala de Aula. São Paulo: Libertad, 1999.

VILLAR, Véra L. C. Diplomados em Serviço Social: a contribuição para a formação profissional - Uma análise do processo de construção do TCC. Relatório de Pesquisa. NEFESS-FSSPUCRS, 2007.

WERNECK, Hamilton. Ousadia de Pensar. 2. Ed. Rio de Janeiro: DP\&A, 2000.

\section{Abstract: \\ Professional formation in Social Service - an emphasis in the process of construction of the TCC}

The present article is part of a product of a qualitative research carried out at one Social Work undergraduate program in the south region of Brazil with the aim of contribute for the qualification of the professional education based on the analysis of the process of construction of TCC (monography) in Social 
Work. The study involved the participation of Social Work graduates and professors, as well as a documental analysis of TCCs, and intended to question this process of evaluation, having as reference the moment of elaboration of final work. We aim to contribute for the identification of positive aspects, difficulties and suggestions concerning the refereed process. The importance of permanently questioning the process of evoluation is emphasized beginning from the hearing of the daily speech of the one who is the protagonist of the education process.

Keywords: Social Work. Monography . Education in Social Work.

Graduates. Professors.

Recebido em novembro de 2009

Aceito em Dezembro de 2009 